The liver is an organ that, due to vascularisation and functions, is prone to metastases. Most liver metastases are observed in cases of gastrointestinal cancers in: stomach, colon, gallbladder, and bile ducts. Metastatic lesions are also observed in lung, breast, thyroid, kidney, and pancreatic cancer. One of the best known and most effective ways of liver lesion treatment is Metastasectomy. Unfortunately, lesions are frequently inoperable. Apart from chemotherapy, it is possible to apply local treatment such as TACE (trans-arterial chemoembolisation), RFA (Radio Frequency Ablation), and SBRT (Stereotactic Body Radiation Therapy). One of the newest methods of inoperable lesion treatment is radioembolisation (SIRT). Intravascular administration of microspheres containing radioisotope $90 \mathrm{Y}$ allows delivery of a higher dose of radiation directly to the tumour than traditional radiation with an external beam, while maintaining a small dose to healthy liver methods. Conducted clinical studies confirm the efficacy and safety of SIRT. It is an interesting alternative to other ways of treatment.

Key words: liver metastases, hepatocellular carcinoma, radioembolisation.

Contemp Oncol (Pozn) 2017; 21 (4): 274-278 DOI: https://doi.org/10.5114/wo.2017.72153

\section{Radioembolization treatment for liver metastases}

\author{
Joanna Kiszka ${ }^{1}$ Bożenna Karczmarek-Borowska ${ }^{1,2}$
}

${ }^{1}$ Subcarpatia Cancer Center in Rzeszow, Poland

${ }^{2}$ Department of Oncology, Faculty of Medicine, University of Rzeszow, Poland

\section{Introduction}

The liver is an organ in which, due to vascularisation and functions, metastases occur frequently. Most liver metastases are observed in cases of gastrointestinal cancers in: stomach, colon, gallbladder, and bile ducts. Metastatic lesions are also observed in lung, breast, thyroid, kidney, and pancreatic cancer [1, 2].

Hepatocellular carcinoma (HCC) constitutes approx. 80\% of primary liver cancers. In Poland, the tumour is annually diagnosed in approx. 1500 patients, it is more common in men, and the peak incidence is between 50 and 60 years of age. In 2011, the incidence rate was 1.4/100,000 women, and 2.8 $/ 100,000$ men [3].

Surgery is the most recognised method of treatment in cases of liver changes. Indications for liver resection are constantly expanded with the progress of knowledge and surgeon's experience.

Stereotactic radiosurgery (stereotactic body radiation therapy - SBRT) is used for the treatment of liver lesions. High-precision treatment of lesions is possible with few side effects thanks to stereotaxy. This method is applicable for tumour sizes of $6-7 \mathrm{~cm}$ as well as in the case of numerous coexisting changes (3-5) [4-6].

In the event of non-operative lesions it is also possible to use radio frequency ablation (RFA), which is based on generating hyperthermia with high frequency current. RFA is a method in patients with lesions up to $35 \mathrm{~mm}$ and can be performed percutaneously and laparoscopically. In the case of larger lesions it cannot be applied, because it increases the risk of local recurrence [7-9].

Another ablation technique is cryotherapy. Frequency of relapse was assessed in patients undergoing resection with cryotherapy and without cryotherapy, and no significant differences were between the study groups [10].

Trans-arterial chemoembolisation (TACE) is technique of treatment that can be useful in cases of non-resectable liver tumours. This method involves intravascular administration of the chemotherapeutic agent to the tumour, and then embolisation of vessels supplying the tumour. The effectiveness of this method is based on a high concentration of chemotherapeutic agent in the tumour and embolisation of vessels supplying the lesion [11-14].

\section{Selective internal radioembolisation}

Healthy liver tissue receives approx. 90\% of blood from the portal vein and a few liver vessels. Tumours located in the liver draw approx. 90\% of vascularisation of the hepatic artery, which is used as a channel for administering a drug directly to the tumour.

One of the newest methods of treatment of neoplastic lesions in the liver using this fact is selective internal radiation therapy (selective internal radiation therapy with SIR-Spheres ${ }^{\circledR}$ Y-90 - SIRT). It involves the administration of polymer microspheres of size of 20-60 microns (approx. one thirtieth of the diameter of a human hair) containing radioactive yttrium (90Y) directly into the tumour vasculature through a catheter. Thanks to this fact spheres administered intravenously are arranged in the capillaries of the tumour. They 
are small enough to fit in the capillaries, but large enough not to move further to the venous system. Each sphere produces beta radiation penetrating the tissue to the depth of $2.5 \mathrm{~mm}$. The half-life of radioactive Yttrium is 64.1 hours, so that the majority (94\%) of radiation is removed from the body within 11 days [15]. This method enables provision of a higher dose of radiation to the tumour than traditional irradiation with external fields, while maintaining a low dose for healthy liver cells (below the limit for hepatocytes). It can be used to treat both primary cancers of the liver, gall bladder and metastatic lesions, which are not eligible for surgery. It is also used as monotherapy in patients who are not candidates for $2^{\text {nd }}$ or $3^{\text {rd }}$ line chemotherapy, during the interval between chemotherapy lines, and together with chemotherapy containing fluorouracil [16-18].

\section{Indications for selective internal radiation therapy}

Indications for spheres treatment with the radiation source are very specific. The lesion in the liver should be inoperable, life expectancy of the patient should be more than 12 months, the patient's general condition should be good $(\mathrm{WHO}<2)$, and the liver efficiency score according to Child-Pugh classification should be class A or B.

Barcelona Clinic Liver Cancer (BCLC) is used in the assessment of the disease to choose the method of treatment in cases of hepatocellular carcinoma. It assesses the patient's condition, liver function according to Child-Pugh, tumour size, number of tumours, the presence of vascular invasion, and distant metastases [19].

According to BCLC criteria, patients eligible for treatment in Stage $B$ are patients with multifocal disease located in both lobes, who cannot be candidates for TACE, while stage C (symptomatic disease with or without angioinvasion) patients qualified for radioembolisation treatment may be those with tumours that infiltrate a segmental or lobar branch of the portal vein. Patients who have failed sorafenib therapy or who have failed chemoembolisation can also benefit from the therapy.

Contraindications to SIRT application are (FDA recommendation):

- prior liver irradiation,

- the coexistence of ascites and/or liver failure,

- the presence of liver dysfunction,

- the presence of metastases to organs other than the liver,
- capecitabine treatment in the last two months before the surgery,

- portal vein thrombosis,

- pregnancy,

- abnormal test results: WBC $<2.5$ thousand, Neu $<1.5$ thousand, PLT < 60 thousand, AST/ALT > $5 \times$ normal, bilirubin $>2 \mathrm{mg} / \mathrm{dl}$, albumin $<3 \mathrm{~g} / \mathrm{dl}$, creatinine $>2.5 \mathrm{mg} / \mathrm{dl}$, - irregularities in the anatomical structure of the venous system in the liver.

Observed side effects include abdominal pain, feeling of tightness in the abdomen, nausea, loss of appetite, and fever. Most often, these symptoms resolve after a week of radioembolisation therapy. Severe complications occur rarely. If the spheres reach another organ (e.g. gall bladder, stomach, intestines, or pancreas), they can cause inflammation and require specialist treatment. Radiation-induced liver disease (RILD) occurs very rarely, it usually develops between 60-90 day after surgery, and is characterised by jaundice, ascites, and an increase in the bilirubin concentration in the blood serum [20-22].

Assessment of the treatment effectiveness in the CT scan can be misleading if it is conducted earlier than 3 months after surgery. Figure 1 shows the metastatic liver lesions before treatment with radioembolization using SIR-spheres. Regression of liver lesions is evident in the CT scan taken in the patient 6 months after the treatment (Fig. 2).

Positron emission tomography (PET-CT) enables assessment the response to therapy earlier and more accurately. Liver MRI using diffusion-weighted imaging (DWI) can assess the efficacy of treatment even earlier, 2 days after the treatment.

\section{Clinical trials evaluating the efficacy of SIRT therapy}

Clinical trials for colorectal cancer are shown in Table 1, and clinical trials for hepatocellular carcinoma are shown in Table 2.

\section{Discussion}

Thelen and his team and Shmitzu et al. compared the efficacy of performing synchronous metastasectomy (simultaneous surgery to remove the primary tumour and metastatic changes in the liver) and metachronous metastasectomy (performed after the surgery of primary tumour removal). It was shown that both methods are
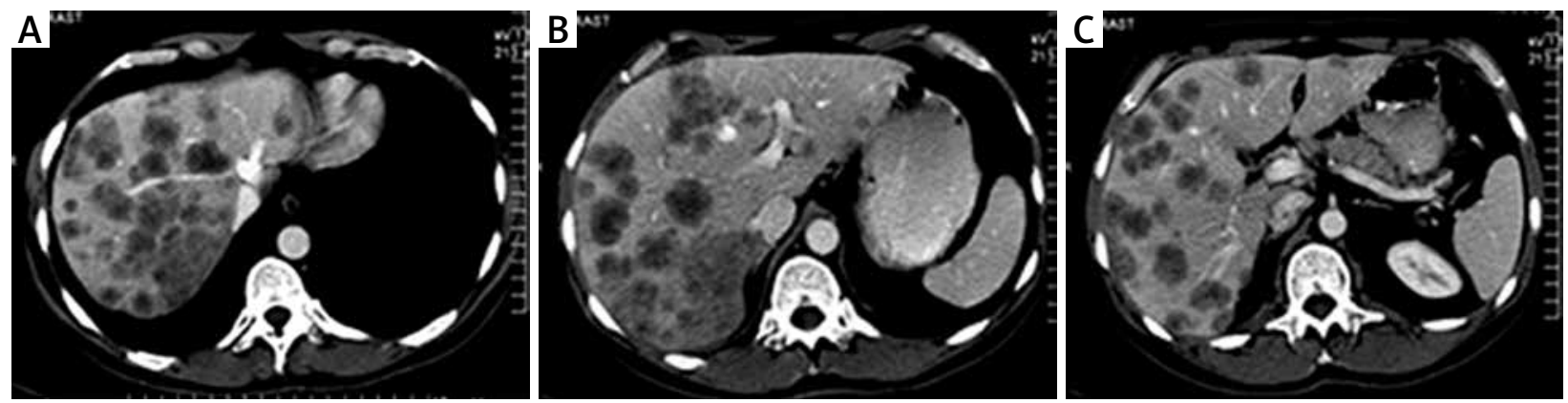

Fig. 1. CT scan before radioembolization therapy using SIR-spheres microspheres (with permission of SIRTEX) 

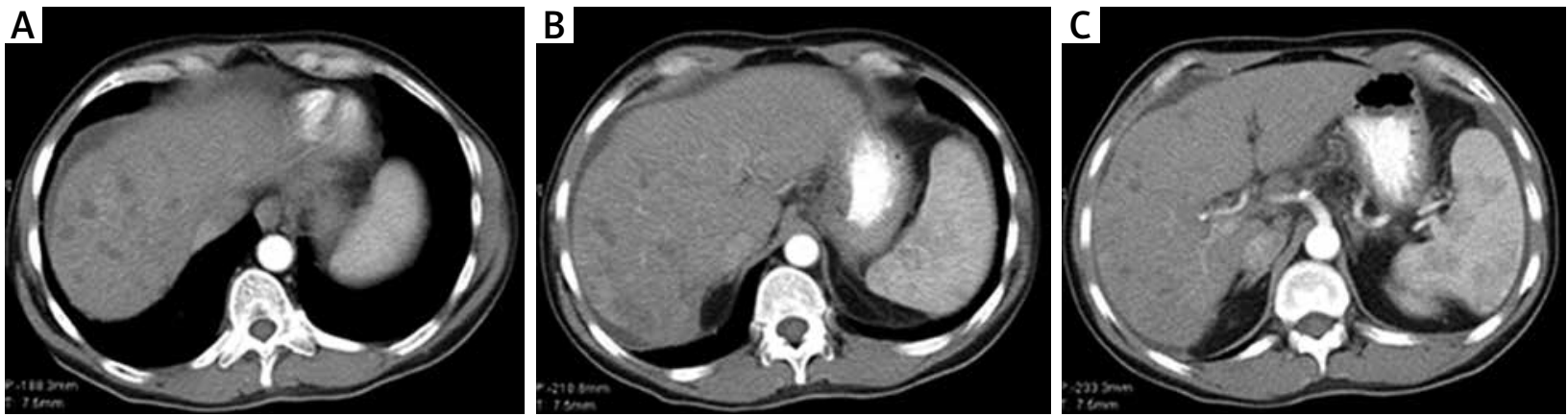

Fig. 2. CT scan 6 months after radioembolization therapy using SIR-spheres microspheres (with permission of SIRTEX)

Table 1. Clinical trials for colorectal cancer [23-25]

\begin{tabular}{|c|c|c|c|c|}
\hline Title & Treatment & Patient number & Location & Result \\
\hline SIRFLOX & $\begin{array}{l}\text { FOLFOX (+/- bevacizumab) vs. } \\
\text { FOLFOX (+/- bevacizumab) } \\
+ \text { SIR-spheres microspheres }\end{array}$ & 530 & Global & $\begin{array}{l}\text { Statistically significant } \\
\text { improvement of } 7.9 \text { months in } \\
\text { median PFS in the liver, from } 12.6 \\
\text { to } 20.5 \text { months representing a } 31 \% \\
\text { reduction in risk of progression in } \\
\text { the liver }\end{array}$ \\
\hline FOXFIRE & $\begin{array}{l}\text { OxMdG (+/- biologic agent) vs. } \\
\text { OxMdG (+/- biologic agent) + SIR- } \\
\text { spheres microspheres }\end{array}$ & $\geq 360$ & UK & Is expected to be released in 2017 \\
\hline HITM-SIR & $\begin{array}{l}\text { anti-CEA CAR-T cells > SIR-spheres } \\
\text { Y-90 resin microspheres }\end{array}$ & 60 & USA & In progress \\
\hline SIR-step & $\begin{array}{l}1^{\text {st-line chemotherapy }} \\
\text { ( } 3 \text { months) followed by: } 5 \text {-FU/ } \\
\text { LV (+/- bevacizumab) vs. } 1^{\text {st-line }} \\
\text { chemotherapy ( } 3 \text { months) followed } \\
\text { by } 5 \text {-FU/LV (+/- bevacizumab) } \\
\text { + SIR-spheres microspheres }\end{array}$ & 162 & Europe & In progress \\
\hline
\end{tabular}

Table 2. Clinical trials for hepatocellular carcinoma $[26,27]$

$\begin{array}{llcc}\text { Title } & \text { Treatment } & \text { Patient number } & \text { Location } \\ \text { SIRveNIB } & \text { Sorafenib vs. SIR-spheres microspheres } & 360 & \text { Asia-Pacific } \\ \text { SARAH } & \text { Sorafenib vs. SIR-spheres microspheres } & 460 & \text { France } \\ \text { SORAMIC } & \text { Sorafenib vs. SIR-spheres microspheres } & 420 & \text { Europe In progress }\end{array}$

comparable, although in the case of two-stage resection respiratory complications occurred more frequently, and hospitalisation time was longer. Postoperative mortality was most often associated with older age (> 70 years) and the extent of surgery. Both papers had a retrospective character $[28,29]$. In the prospective study, Yan et al. assessed relapse-free survival in patients with colorectal cancer treated with synchronous and metachronous liver resection. There were no statistically significant differences between treatments [30]. There are more and more reports of patients undergoing subsequent liver resections. It has been demonstrated that in the case of repeated liver resection, the survival rate and the risk of postoperative complications are comparable to the results obtained after primary liver resection [31].

Nisho et al. evaluated factors affecting survival after subsequent liver resections. It was found that the size of meta- static lesions greater than $50 \mathrm{~mm}$, CEA above $30 \mu \mathrm{g} / \mathrm{l}$, and positive surgical margins across resection have negative impact on the survival after the second liver surgery. The scope of the operation seems to have no effect on survival but may lead to a reduced chance of obtaining a margin free of tumour infiltration in the following resection [32]. Treatment of patients with inoperable lesions in the liver still causes great difficulties. The irradiation of lesions has very limited application due to the sensitivity of liver cells [33, 34].

Chemotherapy and targeted molecular therapy play an important role in the case of liver metastases. Applied chemotherapy regimens are based on 5-fluorouracil with leucovorin with oxaliplatin (FOLFOX), irinotecan (FOLFIRI), or a combination of these drugs (FOLFOXIRI) administered in cycles every 14 days [35-37].

Targeted molecular therapy is bevacizumab (a monoclonal antibody that inhibits angiogenesis by blocking 
VEGF-A). In patients with the expression of epidermal growth factor receptor (EGFR), with normal KRAS gene (after exclusion of mutations in codons 12 and 13 of exon 1) it is possible to provide cetuximab or panitumumab. These drugs are monoclonal antibodies that inhibit EGFR receptor activity, thereby inhibiting signalling pathways associated with the control of cell survival, cell cycle progression, and angiogenesis [38-41].

Recently, the efficacy of SIRT therapy was evaluated in several clinical trials; however, the studies were conducted in small groups of patients (number of patients ranged from 18 to 74) with the exception of the research supervised by Kennedy (a group of 606 patients) and Bester (a group of 224 patients). These studies exclusively recruited patients with metastases to the liver (Tables 1, 2).

All studies demonstrated a significantly longer time to progression (TTS), prolonged overall survival (OS), reduced liver lesions intended for the resection of parts of liver segments in the future, symptoms reduction and bilirubin normalisation in the blood, and liver enzyme activity normalisation.

\section{Summary}

Radioembolisation is a new, less aggressive method of palliative treatment in patients with liver cancer or metastatic disease in the liver. A high dose of radiation to tumour cells is obtained thanks to intra-arterial administration of microscopic spheres containing a radioactive isotope. Clinical studies confirm the efficacy and safety of this method.

Radioembolisation seems to be a promising method of treatment and is an interesting alternative to other methods of treatment used in $1^{\text {st }}$ - $2^{\text {nd }}$ - and $3^{\text {rd }}$-line of treatment.

\section{The authors declare no conflict of interest.}

\section{References}

1. Boyle P, Langman JS. ABC of colorectal cancer: Epidemiology. BMJ 2000; 321: 805-8.

2. Page AJ, Cosgrove DC, Herman JM, Pawlik TM. Advances in understanding of colorectal liver metastasis and implications for the clinic. Expert Rev Gastroenterol Hepatol 2015; 9: 245-59.

3. Itekruse SF, McGlynn KA, Reichman ME. Hepatocellular carcinoma incidence, mortality and survival trends in the United States from 1975 to 2005. J Clin Oncol 2009; 27: 1485-91.

4. Scorsetti M, Comito T, Tozzi A, et al. Final results of a phase II trial for stereotactic body radiation therapy for patients with inoperable liver metastases from colorectal cancer. J Cancer Res Clin Oncol 2015; 141: 543-53.

5. Comito T, Cozzi L, Clerici E, et al. Stereotactic ablative radiotherapy (SABR) in inoperable oligometastatic disease from colorectal cancer: a safe and effective approach. BMC Cancer 2014; 14: 619

6. Janoray G, Mornex F. Follow-up after stereotactic body radiation therapy for liver tumours: A review of the literature and recommendations. Cancer Radiother 2015; 19: 573-81.

7. Vavra P, Novakova J, Ostruszka P, et al. Colorectal cancer liver metastases: laparoscopic and open radiofrequency-assisted surgery. Videosurgery Miniinv 2015; 10: 205-12.

8. Sorensen SM, Mortensen FV, Nielsen DT. Radiofrequency ablation of colorectal liver metastases: long-term survival. Acta Radiol 2007; 48: 253-8.
9. Kariyama K, Wakuta A, Nishimura M, et al. Percutaneous Radiofrequency Ablation for Intermediate-Stage Hepatocellular Carcinoma. Oncology 2015; 89 Suppl 2: 19-26.

10. Niu R, Yan TD, Zhy JC, et al. Recurrence and survival outcomes after hepatic resection with or without cryotherapy of liver metastases from colorectal carcinoma. Ann Surg Oncol 2007; 14: 2078-2087.

11. Lammer J, Malagari K, Vogl T. Prospective randomized study of doxorubicin-eluting-bead embolization in the treatment of hepatocellular carcinoma: result of PRECISION V study. Cardiovasc Intervent Radiol 2010; 33: 41-52.

12. Salhab M, Canelo R. An overview of evidence-based management of hepatocellular carcinoma: a meta-analysis. J Cancer Res Ther 2011; 7: 463-75.

13. Bester L, Meteling B, Boshell D, et al. Transarterial chemoembolisation and radioembolisation for the treatment of primary liver cancer and secondary liver cancer: a review of the literature. J Med Imaging Radiat Oncol 2014; 58: 341-52.

14. Huang W, Yang S, You L, et al. Transcatheter arterial chemoembolisation (TACE) plus S-1 for the treatment of BCLC stage B hepatocellular carcinoma refractory to TACE. Contemp Oncol (Pozn) 2016; 20: 468-74.

15. Jakobs TF, Hoffmann RT, Tatsch K, Trumm C, Reiser MF. Therapy response of liver tumors after selective internal radiation therapy. Radiologe 2008; 48: 839-49.

16. Damm R, Seidensticker R, Ricke J, Seidensticker M. Interventional radiological procedures in the therapy for colorectal liver metastases. Zentralbl Chir 2013; 138: 76-83.

17. Bester L, Hobbins PG, Wang SC, Salem R. Imaging characteristics following 90yttrium microsphere treatment for unresectable liver cancer J Med Imaging Radiat Oncol 2011; 55: 111-8.

18. Raoul JL, Edeline J, Pracht M, Boucher E, Rolland Y, Garin E. Radioembolisation for hepatocellular carcinoma. Cancer Radiother 2011; 15: 64-8

19. Llovet JM, Joshi J., Brux J. Barcelona-Clinic Liver Cancer Group.: The Barcelona approach: diagnosis, staging and treatment of hepatocellular carcinoma. Liver Transpl 2004;10 (2 Suppl 1): S115-20.

20. Strigari L, Sciuto R, Rea S, et al. Efficacy and toxicity related to treatment of hepatocellular carcinoma with 90Y-SIR spheres: radiobiologic considerations. J Nucl Med 2010; 51: 1377-85.

21. Lam MG, Louie JD, Iagaru AH, Goris ML, Sze DY. Safety of repeated yttrium-90 radioembolization. Cardiovasc Intervent Radiol 2013; 36: $1320-8$

22. Townsend A, Price TJ, Patterson K, Pittman K. Fluorouracil-induced hepatic artery spasm preventing yttrium-90 microsphere administration. Clin Nucl Med 2008; 33: 528-30.

23. van Hazel GA, Heinemann V, Sharma NK, et al. SIRFLOX: Randomised Phase III Trial Comparing First-Line m Folfox6 (plus or minus Bevacizumab) versus mFOLFOX6 (plus or minus Bevacizumab) plus Selective Internal Radiation Therapy in patients with metastatic colorectal cancer. J Clin Oncol 2016; 34: 1723-31.

24. Dutton SJ, Kenealy N, Love SB, et al. FOXFIRE protocol: an open-label, randomised, phase III trial of 5-fluorouracil, oxaliplatin and folinic acid (OxMdG) with or without interventional Selective Internal Radiation Therapy (SIRT) as first-line treatment for patients with unresectable liver-only or liver-dominant metastatic colorectal cancer. BMC Cancer 2014; 14: 497.

25. van Hazel GA, Pavlakis N, Goldstein D, et al. Treatment of fluorouracil-refractory patients with liver metastases from colorectal cancer by using yttrium-90 resin microspheres plus concomitant systemic irinotecan chemotherapy. J Clin Oncol 2009; 27: 4089-95.

26. Bhangoo MS, Karnani DR, Hein PN, et al. Radioembolization with Yttrium-90 microspheres for patients with unresectable hepatocellular carcinoma. J Gastrointest Oncol 2015; 6: 469-78.

27. Vilgrain V, Abdel-Rehim M, Sibert A, Ronot M, Lebtahi R, Castéra L, Chatellier G; SARAH Trial Group. Radioembolisation with yttrium-90 microspheres versus sorafenib for treatment of advanced hepatocellular carcinoma (SARAH): study protocol for a randomised controlled trial. Trials 2014; 15: 474.

28. Thelen A, Jonas S, Benckert C, et al. Simultaneous versus staged liver resection of synchronous liver metastases from colorectal cancer. Int J Colorectal Dis 2007; 22: 1269-76. 
29. Smitzu Y, Yasui K, Sano T, et al. Treatment strategy for synchronous metastases of colorectal cancer: is hepatic resection after an observation interval appropriate? Langenbeck's Arch Surg 2007; 392: 535-8.

30. Yan TD, Chu F, Black D, et al. Synchronous resection of colorectal primary cancer and liver metastases. World J Surg 2007; 31: 1496501.

31. Thelen A, Jonas S, Benckert C. Repeat liver resection for recurrent liver metastases from colorectal cancer. Eur J Surg Oncol 2007; 33: 324-8.

32. Nisho H, Hamady ZZR, Malik HZ. Outcome following repeat liver resection for colorectal liver metastases. Eur J Surg Oncol 2007; 33: 729-34.

33. Bydder S, Spry NNA, Christie DR, Roos D, Burmeister BH, Krawitz H. A prospective trial of short-fractionation radiotherapy for the palliation of liver metastases. Australas Radiol 2003; 47: 284-8.

34. Hoyer M, Swaminath A, Bydder S, Lock M, Mendez RA, Kavanagh B. Radiotherapy for liver metastases: a review of evidence. Int J Radiat Oncol Biol Phys 2012; 82: 1047-57.

35. Ciombor KK, Wu C, Goldberg RM. Recent therapeutic advances in the treatment of colorectal cancer. Annu Rev Med 2015; 66: 83-95.

36. Mohelnikova-Duchonova B, Melichar B, Soucek P. FOLFOX/FOLFIRI pharmacogenetics: the call for a personalized approach in colorectal cancer therapy. World J Gastroenterol 2014; 20: 10316-30.

37. Juez I, Rubio C, Figueras J. Multidisciplinary approach of colorectal liver metastases. Clin Transl Oncol 2011; 13: 721-7.

38. Goldstein DA, Zeichner SB, Bartnik CM, Neustadter E, Flowers CR. Metastatic Colorectal Cancer: A Systematic Review of the Value of Current Therapies. Clin Colorectal Cancer 2016; 15: 1-6.

39. Wang G, Kelley RK. Gappnet. KRAS mutational analysis for colorectal cancer: Application pharmacogenomic. PLoS Curr 2010; 2; DOI: 10.1371/currents.RRN1175.

40. Keating GM. Spotlight on panitumumab in metastatic colorectal cancer. BioDrugs 2010; 24: 275-8.

41. Lakomy R, Rogowski W, Piko B, Mihaylova Zh, Pritzova E, Kvocekova L. Prospective noninterventional study on the use of panitumumab monotherapy in patients with recurrent or progressive colorectal cancer: the VECTIS study. Cancer Manag Res 2015; 7 : 311-8.

\section{Address for correspondence}

\section{Joanna Kiszka}

Subcarpatia Cancer Center in Rzeszow

Szopena 2

35-055 Rzeszow, Poland

e-mail: kiszka joanna@wp.pl

Submitted: 1.02.2017

Accepted: 26.08.2017 